\title{
Carta Placuit Deo aos bispos da Igreja católica sobre alguns aspectos da salvação cristã
}

O sumo pontífice Francisco, no dia 16 de fevereiro de 2018, aprovou esta carta, decidida na Sessão Plenária desta Congregação no dia 24 de janeiro de 2018, e ordenou a publicação.

Dado em Roma, na sede da Congregação para a Doutrina da Fé, no dia 22 de fevereiro de 2018, Festa da Cátedra de São Pedro.

\section{INTRODUÇÃO}

1. "Aprouve a Deus na sua bondade e sabedoria, revelar-se a $\mathrm{Si}$ mesmo e dar a conhecer o mistério da sua vontade (cfr. Ef 1,9), segundo o qual os homens, por meio de Cristo, Verbo encarnado, têm acesso ao Pai no Espírito Santo e se tornam participantes da natureza divina (cfr. Ef 2,18; 2 Pe 1,4). [...] Porém, a verdade profunda tanto a respeito de Deus como a respeito da salvação dos homens, manifesta-se-nos, por esta revelação, em Cristo, que é, simultaneamente, o mediador e a plenitude de toda a revelação".[1] O ensinamento sobre a salvação em Cristo exige sempre ser aprofundado novamente. A Igreja, tendo o olhar fixo em Cristo Senhor, dirigese com amor materno a todos os homens, para anunciar-lhes o inteiro desígnio de Aliança do Pai que, mediante o Espírito Santo, deseja "submeter tudo a Cristo" (Ef 1,10). A presente Carta pretende destacar, na linha da grande tradição da fé e com especial referência ao ensinamento de Papa Francisco, alguns aspectos da salvação cristã que possam ser hoje difíceis de compreender por causa das recentes transformações culturais.

\section{O IMPACTO DAS TRANSFORMAÇÕES CULTURAIS DE HOJE SOBRE O SIGNIFICADO DA SALVAÇÃO CRISTÃ}

2. O mundo contemporâneo questiona, não sem dificuldade, a confissão de fé cristã, que proclama Jesus o único Salvador de todo o homem e da humanidade inteira (cf. At 4,12; Rom 3,23-24; 1 Tm 2,4-5; Tit 2,11-15).[2] Por um lado, o individualismo centrado no sujeito autônomo, tende a ver o homem como um ser cuja realização depende somente das suas forças.[3] Nesta visão, a figura de Cristo corresponde mais a um modelo que inspira ações generosas, mediante suas palavras e seus gestos, do que Aquele que transforma a condição humana, incorporando-nos numa nova existência reconciliada com o Pai e entre nós, mediante o Espírito (cf. 2 Cor 5,19; Ef 2,18). Por outro lado, difunde-se a visão de uma salvação meramente interior, que talvez suscita uma forte convicção pessoal ou um sentimento intenso de estar unido 
a Deus, mas sem assumir, curar e renovar as nossas relações com os outros e com o mundo criado. Com esta perspectiva, torna-se difícil compreender o significado da Encarnação do Verbo, através da qual Ele se fez membro da família humana, assumindo a nossa carne e a nossa história, por nós homens e para a nossa salvação.

3. O Santo Padre Francisco, no seu magistério ordinário, referiu-se muitas vezes a duas tendências que representam os dois desvios antes mencionados, e que se assemelham em alguns aspectos a duas antigas heresias, isto é, o pelagianismo e o gnosticismo. [4] Prolifera em nossos tempos um neopelagianismo em que o homem, radicalmente autônomo, pretende salvar-se a si mesmo sem reconhecer que ele depende, no mais profundo do seu ser, de Deus e dos outros. A salvação é então confiada às forças do indivíduo ou a estruturas meramente humanas, incapazes de acolher a novidade do Espírito de Deus.[5] Um certo neognosticismo, por outro lado, apresenta uma salvação meramente interior, fechada no subjetivismo.[6] Essa consiste no elevar-se "com o intelecto para além da carne de Jesus rumo aos mistérios da divindade desconhecida".[7] Pretende-se, assim, libertar a pessoa do corpo e do mundo material, nos quais não se descobrem mais os vestígios da mão providente do Criador, mas se vê apenas uma realidade privada de significado, estranha à identidade última da pessoa e manipulável segundo os interesses do homem.[8] Por outro lado, é claro que a comparação com as heresias pelagiana e gnóstica pretende somente evocar traços gerais comuns, sem entrar, nem fazer juízos, sobre a natureza destes erros antigos. De fato, a diferença entre o contexto histórico secularizado de hoje e o contexto dos primeiros séculos cristãos, nos quais estas heresias nasceram, é grande.[9] Todavia, enquanto o gnosticismo e o pelagianismo representam perigos perenes de equívocos da fé bíblica, é possível encontrar uma certa familiaridade com os movimentos de hoje apenas referidos acima.

4. Seja o individualismo neopelagiano que o desprezo neognóstico do corpo, descaracterizam a confissão de fé em Cristo, único Salvador universal. Como poderia Cristo mediar a Aliança da família humana inteira, se o homem fosse um indivíduo isolado, que si autorrealiza somente com as suas forças, como propõe o neopelagianismo? E como poderia chegar até nós a salvação mediante a Encarnação de Jesus, a sua vida, morte e ressurreição no seu verdadeiro corpo, se aquilo que conta fosse somente libertar a interioridade do homem dos limites do corpo e da matéria, segundo a visão neognóstica? Diante destas tendências, esta Carta pretende reafirmar que, a salvação consiste na nossa união com Cristo, que, com a sua Encarnação, vida, morte e ressurreição, gerou uma nova ordem de relações com o Pai e entre os homens, e nos introduziu nesta ordem graças ao dom do seu Espírito, para que possamos unir-nos ao Pai como filhos no Filho, e formar um só corpo no "primogênito de muitos irmãos" (Rom 8,29).

\section{O DESEJO HUMANO DE SALVAÇÃO}

5. O homem percebe, direta ou indiretamente, de ser um enigma: eu existo, mas quem sou eu? Tenho em mim o princípio da minha existência? Toda pessoa, a seu modo, procura a felicidade 


\section{Revista Brasileira de Diálogo Ecumênico e Inter-religioso}

e tenta alcançá-la recorrendo aos meios disponíveis. No entanto, esse desejo universal não é necessariamente expresso ou declarado; ao contrário, esse é mais secreto e oculto do que parece, e está pronto a revelar-se diante de situações específicas. Com frequência, tal desejo coincide com a esperança da saúde física, às vezes assume a forma de ansiedade por um maior bem-estar econômico, mais difusamente expressa-se através da necessidade de uma paz interior e de uma convivência pacífica com o próximo. Por outro lado, enquanto o desejo de salvação se apresenta como um compromisso na direção de um bem maior, esse conserva também uma característica de resistência e de superação da dor. Ao lado da luta pela conquista do bem se coloca a luta de defesa do mal: da ignorância e do erro, da fragilidade e da fraqueza, da doença e da morte.

6. Com relação a estas aspirações, a fé em Cristo ensina-nos, rejeitando qualquer pretensão de autorealização, que as mesmas somente podem realizar-se plenamente se Deus mesmo as torna possíveis, atraindo-nos a Ele. A salvação plena da pessoa não consiste nas coisas que o homem poderia obter por si mesmo, como o ter ou o bem-estar material, a ciência ou a técnica, o poder ou a influência sobre os outros, a boa fama ou a autorealização.[10] Nada da ordem do criado pode satisfazer completamente ao homem, porque Deus nos destinou à comunhão com Ele, e o nosso coração permanecerá inquieto até que não repouse Nele.[11] "A vocação última de todos os homens é realmente uma só, a divina".[12] A revelação, desta forma, não se limita a anunciar

a salvação como resposta à expectativa contemporânea. "Se a redenção, ao contrário, devesse ser julgada ou medida pela necessidade existencial dos seres humanos, como poderíamos evitar a suspeita de termos simplesmente criado um Deus-Redentor à imagem de nossas próprias necessidades?”.[13]

7. Além disso, é necessário afirmar que, segundo a fé bíblica, a origem do mal não se encontra no mundo material e corpóreo, experimentado como um limite e como uma prisão da qual deveríamos ser salvos. Pelo contrário, a fé proclama que o mundo inteiro é bom, enquanto criado por Deus (cf. Gen 1,31; Sab 1,13-14; 1Tim 4,4), e que o mal que mais prejudica o homem é aquele que provém do seu coração (cf. Mt 15,18-19; Gen 3,1-19). Pecando, o homem abandonou a fonte do amor, e se perde em falsas formas de amor, que o fecham cada vez mais em si mesmo. É esta separação de Deus - isto é, Daquele que é fonte de comunhão e de vida que leva à perda de harmonia entre os homens e dos homens com o mundo, introduzindo a desintegração e a morte (cf. Rom 5,12). Consequentemente, a salvação que a fé nos anuncia não diz unicamente respeito à nossa interioridade, mas ao nosso ser integral. De fato, é a pessoa inteira, em corpo e alma, criada pelo amor de Deus à sua imagem e semelhança, que é chamada a viver em comunhão com Ele.

\section{CRISTO, SALVADOR E SALVAÇÃO}

8. Em nenhum momento do caminho do homem, Deus deixou de oferecer a sua salvação aos filhos de Adão (cf. Gen 3,15), estabelecendo uma Aliança com todos os homens em Noé (cf. Gen 9,9) e, mais adiante, com Abraão e a sua descendência (cf. Gn 15,18). Assim, a salvação Caminhos de Diálogo, Curitiba, ano 6, n. 9, p. 206-213, jul./dez. 2018 
divina assume a ordem da criação compartilhada por todos os homens e percorre os seus caminhos concretos na história. Escolhendo para Si um povo, a quem ofereceu os meios para lutar contra o pecado e para se aproximar Dele, Deus preparou a vinda de «um poderoso Salvador, na casa de David, seu servidor» $($ Lc 1,69). Na plenitude dos tempos, o Pai enviou ao mundo seu Filho, o qual anunciou o reino de Deus, curando todo tipo de doenças (cf. Mt 4,23). As curas realizadas por Jesus, através das quais se tornava presente a providência de Deus, eram um sinal que se referia à sua pessoa, Àquele que se revelou plenamente como Senhor da vida e da morte no acontecimento pascal. Segundo o Evangelho, a salvação para todos os povos começa com o acolhimento de Jesus: "Hoje veio a salvação a esta casa" (Lc 19,9). A Boa Nova da salvação tem um nome e um rosto: Jesus Cristo, Filho de Deus Salvador. "No início do ser cristão, não há uma decisão ética ou uma grande ideia, mas o encontro com um acontecimento, com uma Pessoa que dá à vida um novo horizonte e, desta forma, o rumo decisivo".[14]

9. Ao longo da sua tradição secular, a fé cristã tornou presente, através de muitas figuras, a obra salvífica do Filho encarnado. Fê-lo sem nunca separar o aspecto regenerador da salvação, no qual Cristo nos resgata do pecado, do aspecto da elevação, pelo qual Ele nos faz filhos de Deus, participantes da sua natureza divina (cf. 2 Pe 1,4). Considerando a perspectiva salvífica no seu significado descendente, isto é, a partir de Deus que vem para resgatar os homens, Jesus é iluminador e revelador, redentor e libertador; Aquele que diviniza o homem e o justifica. Assumindo a perspectiva ascendente, isto é, a partir dos homens que se dirigem a Deus, Ele é Aquele que, como Sumo Sacerdote da Nova Aliança, oferece ao Pai o culto perfeito em nome dos homens: se sacrifica, repara os nossos pecados e permanece sempre vivo para interceder a nosso favor. Desta forma, verifica-se na vida de Jesus uma sinergia maravilhosa do agir divino com o agir humano, que mostra a falta de fundamento de uma perspectiva individualista. Assim, por um lado, o sentido descendente testemunha a primazia absoluta da ação gratuita de Deus; a humildade em receber os dons de Deus, antes mesmo do nosso agir, é essencial para poder responder ao seu amor salvífico. Por outro lado, o sentido ascendente recorda-nos que, através do agir plenamente humano de seu Filho, o Pai quis regenerar o nosso agir, para que, assemelhados a Cristo, possamos realizar "as boas obras que Deus de antemão preparou para nelas caminharmos" (Ef 2,10).

10. Para além disso, é claro que a salvação que Jesus trouxe na sua própria pessoa não se realiza somente de modo interior. Assim, para poder comunicar a cada pessoa a comunhão salvífica com Deus, o Filho se fez carne (cf. Jo 1,14). É exatamente assumindo a carne (cf. Rom 8,3; Heb 2,14; 1 Jo 4,2), e nascendo de uma mulher (cf. Gal 4,4), que "o Filho de Deus se fez filho do homem" 15$]$ e, também, nosso irmão (cf. Heb 2,14). Assim, entrando a fazer parte da família humana, "uniu-se de certo modo a cada homem" [16] e estabeleceu uma nova ordem nas relações com Deus, seu Pai, e com todos os homens, na qual podemos ser incorporados para participar na sua própria vida. Consequentemente, assumir a carne humana, longe de limitar a 


\section{Revista Brasileira de Diálogo Ecumênico e Inter-religioso}

ação salvífica de Cristo, permite-Lhe mediar de maneira concreta a salvação de Deus com todos os filhos de Adão.

11. Concluindo, e para responder, quer seja ao reducionismo individualista da tendência pelagiana, quer seja ao reducionismo neognóstico que promete uma libertação interior, é necessário recordar o modo como Jesus é Salvador. Ele não se limitou a mostrar-nos o caminho para encontrar Deus, isto é, um caminho que poderemos percorrer por nós mesmos, obedecendo às suas palavras e imitando o seu exemplo. Cristo, todavia, para abri-nos a porta da libertação, tornou-se Ele mesmo o caminho: "Eu sou o caminho" (Jo 14,6).[17] Além disso, esse caminho não é um percurso meramente interior, à margem das nossas relações com os outros e com o mundo criado. Pelo contrário, Jesus ofereceu-nos um "caminho novo e vivo que Ele abriu para nós através [...] da sua carne" (Heb 10,20). Enfim, Cristo é Salvador porque Ele assumiu a nossa humanidade integral e viveu em plenitude a vida humana, em comunhão com o Pai e com os irmãos. A salvação consiste em incorporar-se nesta vida de Cristo, recebendo o seu Espírito (cf. 1 Jo 4,13). Assim, Ele tornou-se "em certo modo, o princípio de toda graça segundo a humanidade".[18] Ele é, ao mesmo tempo, o Salvador e a Salvação.

\section{A SALVAÇÃO NA IGREJA, CORPO DE CRISTO}

12. O lugar onde recebemos a salvação trazida por Jesus é a Igreja, comunidade daqueles que, tendo sido incorporados à nova ordem de relações inaugurada por Cristo, podem receber a plenitude do Espírito de Cristo (cf. Rom 8,9). Compreender esta mediação salvífica da Igreja é uma ajuda essencial para superar qualquer tendência reducionista. De fato, a salvação que Deus nos oferece não é alcançada apenas pelas forças individuais, como gostaria o neopelagianismo, mas através das relações nascidas do Filho de Deus encarnado e que formam a comunhão da Igreja. Além disso, uma vez que a graça que Cristo nos oferece não é, como afirma a visão neognóstica, uma salvação meramente interior, mas que nos introduz nas relações concretas que Ele mesmo viveu, a Igreja é uma comunidade visível: nela tocamos a carne de Jesus, de maneira singular nos irmãos mais pobres e sofredores. Enfim, a mediação salvífica da Igreja, "sacramento universal de salvação",[19] assegura-nos que a salvação não consiste na autorealização do indivíduo isolado, e, muito menos, na sua fusão interior com o divino, mas na incorporação em uma comunhão de pessoas, que participa na comunhão da Trindade.

13. Tanto a visão individualista como a visão meramente interior da salvação contradizem a economia sacramental, através da qual Deus quis salvar a pessoa humana. A participação, na Igreja, à nova ordem de relações inauguradas por Jesus realiza-se por meio dos sacramentos, entre eles, o Batismo que é a porta,[20] e a Eucaristia que é fonte e culmine.[21] Assim, se vê, a inconsistência das pretensões de autosalvação, que contam apenas com as forças humanas. Pelo contrário, a fé confessa que somos salvos por meio do Batismo, que imprime o caráter indelével de pertencer a Cristo e à Igreja, do qual deriva a transformação do nosso modo concreto de viver as relações com Deus, com os homens e com a criação (cf. Mt 28,19). Assim, purificados do Caminhos de Diálogo, Curitiba, ano 6, n. 9, p. 206-213, jul./dez. 2018 
pecado original e de todo pecado, somos chamados a uma nova vida em conformidade com Cristo (cf. Rom 6,4). Com a graça dos sete sacramentos, os crentes continuamente crescem e se regeneram, sobretudo, quando o caminho se torna mais difícil e as quedas não faltam. Quando eles pecam, abandonam o amor por Cristo, podendo ser reintroduzidos, por meio do sacramento da Penitência, à ordem das relações inaugurada por Jesus, para caminhar como Ele caminhou (cf. 1 Jo 2,6). Desta forma, olhamos com esperança para o juízo final, no qual cada pessoa será julgada pelo amor (cf. Rm 13,8-10), especialmente pelos mais fracos (cf. Mt 25,31-46).

14. A economia salvífica sacramental opõe-se ainda às tendências que propõem uma salvação meramente interior. De fato, o gnosticismo está associado a um olhar negativo sobre a ordem da criação, inclusive, como uma limitação da liberdade absoluta do espírito humano. Consequentemente, a salvação é vista como libertação do corpo e das relações concretas que a pessoa vive. Pelo contrário, como somos salvos "por meio da oferta do corpo de Jesus Cristo" (Heb 10,10; cf. Col 1,22), a verdadeira salvação, longe de ser libertação do corpo, compreende também a sua santificação (cf. Rom 12,1). O corpo humano foi modelado por Deus, que nele inscreveu uma linguagem que convida a pessoa humana a reconhecer os dons do Criador e a viver em comunhão com os irmãos.[22] O Salvador restabeleceu e renovou, com a sua Encarnação e o seu mistério pascal, esta linguagem originária, e comunicou-a na economia corporal dos sacramentos. Graças aos sacramentos, os cristãos podem viver fielmente à carne de Cristo e, consequentemente, em fidelidade à ordem concreta das relações que Ele nos deu. Esta ordem de relações requer, de maneira especial, o cuidado pela humanidade sofredora de todos os homens, através das obras de misericórdia corporais e espirituais.[23]

\section{CONCLUSÃO}

15. A consciência da vida plena, na qual Jesus Salvador nos introduz, impulsiona os cristãos à missão de proclamar a todos os homens a alegria e a luz do Evangelho.[24] Neste esforço, eles estarão também prontos para estabelecer um diálogo sincero e construtivo com os crentes de outras religiões, na confiança que Deus pode conduzir à salvação em Cristo "todos os homens de boa vontade, em cujos corações a graça opera ocultamente".[25] Ao dedicar-se com todas as suas forças à evangelização, a Igreja continua a invocar a vinda definitiva do Salvador, porque "na esperança fomos salvos" (Rom 8,24). A salvação do homem será plena somente quando, depois de ter vencido o último inimigo, a morte (cf 1 Cor 15,26), participaremos plenamente da glória de Cristo ressuscitado, que leva à plenitude a nossa relação com Deus, com os irmãos e com toda a criação. A salvação integral, da alma e do corpo, é o destino final ao qual Deus chama todos os homens. Fundamentados na fé, sustentados pela esperança, operantes na caridade, seguindo o exemplo de Maria, a Mãe do Salvador e a primeira dos que foram salvos, estamos certos de que nossa cidadania "está nos céus, de onde certamente esperamos o Salvador, o Senhor Jesus Cristo. Ele transfigurará o nosso pobre corpo, conformando-o ao seu 
Revista Brasileira de Diálogo Ecumênico e Inter-religioso

corpo glorioso, com aquela energia que o torna capaz de a si mesmo sujeitar todas as coisas" (Fil 3,20-21).

\title{
Congregação para a Doutrina da Fé
}

\author{
+ Luis F. Ladaria, S.I. \\ Arcebispo titular de Thibica \\ Prefeito
}

\author{
+ Giacomo Morandi \\ Arcebispo titular de Cerveteri \\ Secretário
}

[1] Conc. Ecum. Vat. II, Const. dogm. Dei Verbum, n. 2.

[2] Cf. Congregação para a Doutrina da Fé, Decl. Dominus Iesus (6 de agosto de 2000), nn. 58: AAS 92 (2000), 745-749.

[3] Cf. Francisco, Exort. apost. Evangelii gaudium(24 de novembro de 2013), n. 67: AAS105 (2013), 1048.

[4] Cf. Id., Carta enc. Lumen fidei (29 de junho de 2013), n. 47: AAS 105 (2013), 586-587; Exort. apost. Evangelii gaudium, nn. 93-94: AAS (2013), 1059; Discurso aos representantes do V Congresso nacional da Igreja italiana, Florença (10 de novembro de 2015): AAS 107 (2015), 1287.

[5] Cf. Id., Discurso aos representantes do V Congresso nacional da Igreja italiana, Florença (10 de novembro de 2015): AAS 107 (2015), 1288.

[6] Cf. Id., Exort. apost. Evangelii gaudium, n. 94: AAS105 (2013), 1059: «o fascínio do gnosticismo, uma fé fechada no subjetivismo, onde apenas interessa uma determinada experiência ou uma série de raciocínios e conhecimentos que supostamente confortam e iluminam, mas, em última instância, a pessoa fica enclausurada na imanência da sua própria razão ou dos seus sentimentos»; Pontifício Conselho para a Cultura - Pontifício Conselho para o diálogo Inter-religioso, Jesus Cristo, portador da água viva. Uma reflexão cristã sobre a " $N e w$ Age" (janeiro de 2003), Cidade do Vaticano 2003.

[7] Francisco, Carta enc. Lumen fidei, n. 47: AAS 105 (2013), 586-587.

[8] Cf. Id., Discurso aos participantes da peregrinação da diocese de Brescia (22 de junho de 2013): AAS 95 (2013), 627: "neste mundo onde nega-se o homem, onde se prefere andar na estrada do gnosticismo, [...] do 'sem carne' - um Deus que não se fez carne [...]".

[9] De acordo com a heresia Pelagiana, desenvolvida durante o século V ao redor de Pelágio, o homem, para cumprir os mandamentos de Deus e ser salvo, precisa da graça apenas como um auxílio externo à sua liberdade (como luz, exemplo, força), mas não como uma sanação e regeneração radical da liberdade, sem mérito prévio, para que ele possa realizar o bem e Caminhos de Diálogo, Curitiba, ano 6, n. 9, p. 206-213, jul./dez. 2018

212 ISSN 2595-8208 
alcançar a vida eterna. Mais complexo é o movimento gnóstico, surgido nos séculos I e II, que manifestou-se de formas muito diferentes. Em geral, os gnósticos acreditavam que a salvação é obtida através de um conhecimento esotérico ou "gnose". Esta gnose revela ao gnóstico sua essência verdadeira, isto é, uma centelha do Espírito divino que habita em sua interioridade, que deve ser libertada do corpo, estranho à sua verdadeira humanidade. Somente assim o gnóstico retorna ao seu ser originário em Deus, de quem ele afastou-se pela queda original.

[10] Cf. Tomás, Summa theologiae, I-II, q. 2.

[11] Cf. Agostinho, Confissões, I, 1: Corpus Christianorum, 27,1.

[12] Conc. Ecum. Vat. II, Const. past. Gaudium et spes, n. 22.

[13] Comissão Teológica Internacional, Algumas questões sobre a teologia da redenção, 1995, n. 2.

[14] Bento XVI, Carta enc. Deus caritas est (25 de dezembro de 2005), n. 1: AAS 98 (2006), 217; cf. Francisco, Exort. apost. Evangelii gaudium, n. 3: AAS 105 (2013), 1020.

[15] Irineu, Adversus haereses, III, 19,1: Sources Chrétiennes, 211, 374.

[16] Conc. Ecum. Vat. II, Const. past. Gaudium et spes, n. 22.

[17] Cf. Agostinho, Tractatus in Ioannem, 13, 4: Corpus Christianorum, 36, 132: «Eu sou o caminho, a verdade e a vida (Jo 14, 6). Se você busca a verdade, siga o caminho; porque o caminho é o mesmo que a verdade. A meta que se busca e o caminho que se deve percorrer, são a mesma coisa. Não se pode alcançar a meta seguindo um outro caminho; por outro caminho não se pode alcançar a Cristo: a Cristo se pode alcançar somente através de Cristo. Em que sentido se chega a Cristo através de Cristo? Se chega a Cristo Deus através de Cristo homem; por meio do Verbo feito carne se chega ao Verbo que era no princípio Deus junto a Deus.

[18] Tomás, Quaestio de veritate, q. 29, a. 5, co.

[19] Conc. Ecum. Vat. II, Const. dogm. Lumen gentium, n. 48.

[20] Cf. Tomás, Summa theologiae, III, q. 63, a. 6.

[21] Cf. Conc. Ecum. Vat. II, Const. dogm. Lumen gentium, n. 11; Const. Sacrosanctum Concilium, n. 10.

[22] Cf. Francisco, Carta enc. Laudato si' (24 de maio de 2015), n. 155: AAS 107 (2015), 909910.

[23] Cf. Id., Carta apost. Misericordia et misera (20 de novembro de 2016), n. 20: AAS 108 (2016), 1325-1326.

[24] Cf. João Paulo II, Carta enc. Redemptoris missio (7 de dezembro de 1990), n.40: AAS 83 (1991), 287-288; Francisco, Exort. apost. Evangelii gaudium, nn. 9-13: AAS105 (2013), 10221025.

[25] Conc. Ecum. Vat. II, Const. past. Gaudium et spes, n. 22. 